\title{
Control-oriented analysis of a lean-burn light-duty natural gas research engine with scavenged pre-chamber ignition
}

Natural gas is well-suited as a fuel in the transport sector. Due to its excellent combustion characteristics, engines operating with compressed natural gas (CNG) reach high efficiency, especially when operated at lean conditions. However, CNG engine research mainly focusses on stoichiometric conditions in order to use a three-way catalytic converter for the exhaust gas after treatment system.

With the objective to explore the potential of CNG engines operated at lean conditions, a turbo-charged CNG engine with high compression ratio is developed and optimized for lean operation. In order to increase the ignition energy for very lean operation, the CNG engine is equipped with scavenged pre-chambers. For this engine a specific control structure is developed, which allows to operate the engine at a pre-defined (lean) air-to-fuel ratio. Further functionalities such as the combustion placement control and algorithms to estimate the conditions inside of the pre-chamber are implemented.

The first part of this paper describes this engine control structure, which is specifically developed for the lean-burn CNG engine. In the second part, the effects of pre-chamber scavenging on engine performance criteria such as the combustion stability, engine efficiency or engine emissions are analyzed. With the objective to use pre-chamber scavenging to improve engine performance, a scavenging feedback control strategy is proposed. Depending on the air-to-fuel ratio of the main chamber, this strategy adapts the amount of CNG injected into the pre-chamber with a linear controller or an extremum seeking algorithm in order to control the ignition delay.

Key words: gas engine control, pre-chamber ignition, ignition delay control, extremum seeking

\section{Introduction}

Natural gas as a fuel for passenger cars is a promising alternative to Diesel or gasoline [8]. Due to its chemical composition, it has lower $\mathrm{CO}_{2}$ emissions and it can be blended or substituted with renewable alternatives like biogas or synthetic methane. It is highly knock resistant and can be used in engines with high compression ratio, which promotes the engine efficiency [7].

Operated at stoichiometric conditions with a three-way catalytic converter, natural gas engines reach very low emissions [2]. However, efficiency could be increased if the engine is operated under lean conditions due to reduced wall heating and pumping losses [4]. Within a research project with the objective to investigate the efficiency potential and emission characteristics at lean operation, a natural gas engine is set up on a test bench. In order to ignite lean mixtures, the engine is equipped with scavenged pre-chambers, as described in [10].

For the operation of this research engine, a custom engine control strategy is developed and implemented. It offers extended functionalities such as the combustion placement feedback control and the precise control of lean air-to-fuel ratios. Further it allows to set a specific CNG mass to be injected into the pre-chambers in order to increase the ignition energy for lean mixtures. The implemented engine control strategy, which is described in section 2, is then used to investigate lean CNG combustion with scavenged pre-chambers. Results of this analysis are presented in [10]. Further, a control-oriented analysis of the effect of pre-chamber scavenging on engine efficiency and emissions is conducted and used to propose a pre-chamber scavenging control. This analysis is described in section 3 and the control proposal is presented in section 4.
Pre-chamber combustion for lean gas engine operation is well known in literature [1,9]. However, to the authors knowledge, there is no literature about pre-chamber scavenging feedback control.

\section{Research engine setup and control structure}

\subsection{Engine schematics with sensors \& actuators}

There are two gas engine configurations to be controlled, one standard version (engine 1) and one extended version with scavenged pre-chambers (engine 2). Except for the ignition system, both engines are identical. They are based on a four cylinder passenger car Diesel engine, which was adapted to run with compressed natural gas (CNG). A characterization of these engines can be found in [10].

Figure 1 shows a schematic of the research gas engine 2. Seven actuators are used to control the engine, as they are labeled in the schematic. The air mass flow through the engine is controlled by the waste gate valve $\left(\mathrm{u}_{\mathrm{WG}}\right)$ and the throttle $\left(\mathrm{u}_{\mathrm{Thr}}\right)$ in front of the intake. The amount of CNG, which is pre-mixed with the air can be controlled with the energizing duration of the mixer injectors in front of the throttle $\left(\mathrm{DOE}_{\mathrm{Mix}}\right)$ and the mixer rail pressure regulator $\left(\mathrm{u}_{\mathrm{PR}, \mathrm{Mix}}\right)$. The timing and the amount of $\mathrm{CNG}$ injected into the pre-chambers can be controlled by the pre-chamber injector control signals $\left(\mathrm{SOE}_{\mathrm{PC}}, \mathrm{DOE}_{\mathrm{PC}}\right)$ as well as the prechamber rail pressure regulator $\left(\mathrm{u}_{\mathrm{PR}, \mathrm{PC}}\right)$. The combustion placement ${ }^{1}$ is controlled by the spark timing $\left(\mathrm{CA}_{\text {Ign }}\right)$. The ignition coil dwell time is set to a constant value of $2 \mathrm{~ms}$.

Hence, a total of four main engine operation parameters are controlled by these seven actuators. However, these parameters are not intuitive to use as reference signals. In

${ }^{1}$ Here, the combustion placement refers to the crank angle at which $50 \%$ of fuel is burned (CA50). 
a quantitative control approach as is chosen here, the reference signals of interest are the engine torque and the air-tofuel ratio of the air-CNG gas mixture in the combustion chamber. For a constant air-to-fuel ratio, the engine torque is approximately proportional to the air mass flow. Therefore, instead of controlling the air mass flow, the throttle and the waste gate are used to control the engine torque directly, and instead of the amount of CNG, the mixer injectors and the mixer rail pressure are used to control the air-to-fuel ratio. However, torque and air-to-fuel ratio are strongly coupled variables. A change in one of them will act as a disturbance for the other one. These cross-coupling effects need to be considered in the control structure.
Figure 2 shows a signal flow chart of the engine in its test bench environment. The four reference signals can be set by the test bench operator via the test bench operating system. These parameters are transmitted to the engine control unit (ECU) via a controller area network (CAN) bus connection. As illustrated in the signal flow chart, the implemented feedback algorithms on the ECU use a number of sensor signals and combustion characteristics to derive all the control signals. These control signals are then transmitted to a power stage (dSpace RapidPro), which translates them to analog signals, able to actuate the corresponding actuators.

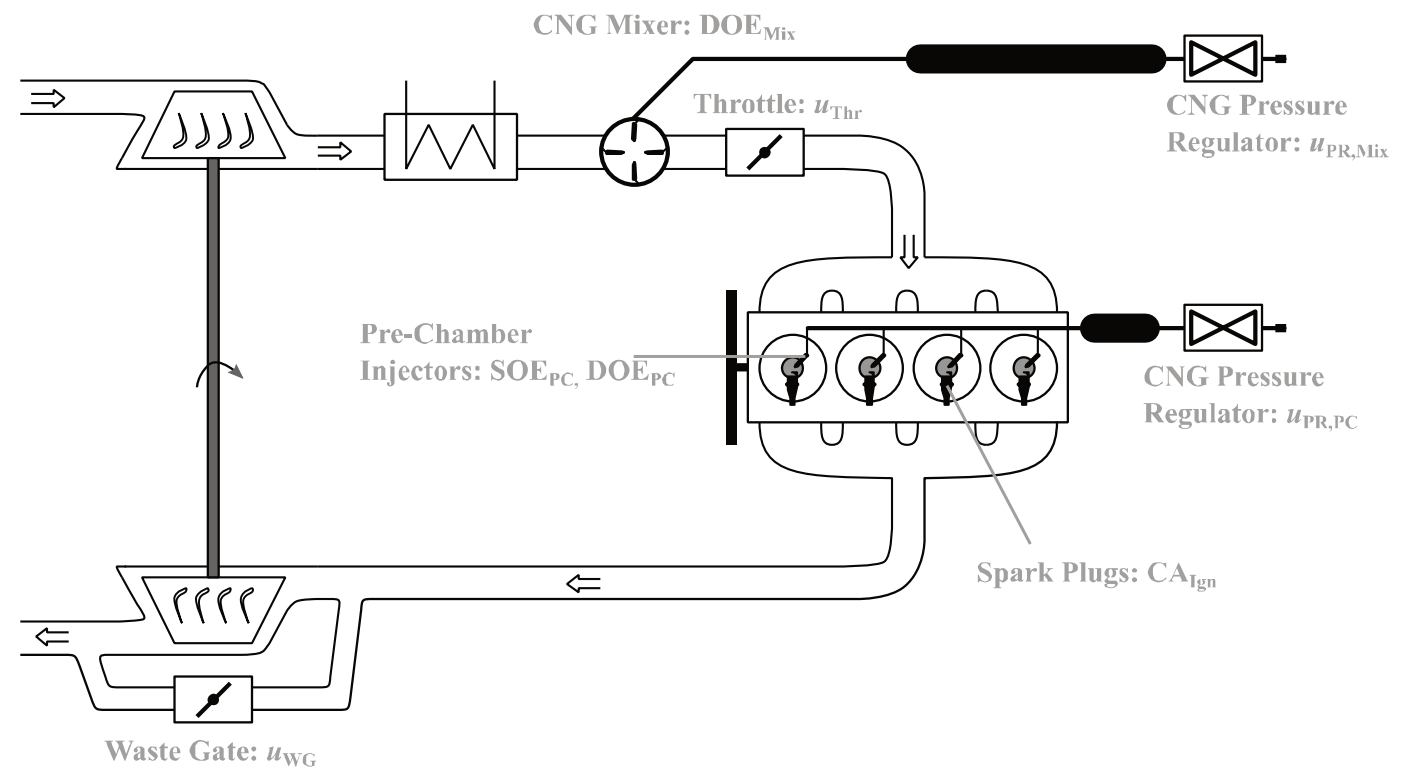

Fig. 1. Schematic of the research gas engine with scavenged pre-chambers (engine 2). Engine actuators and their corresponding control variables (referred to as actuator signals) are labeled

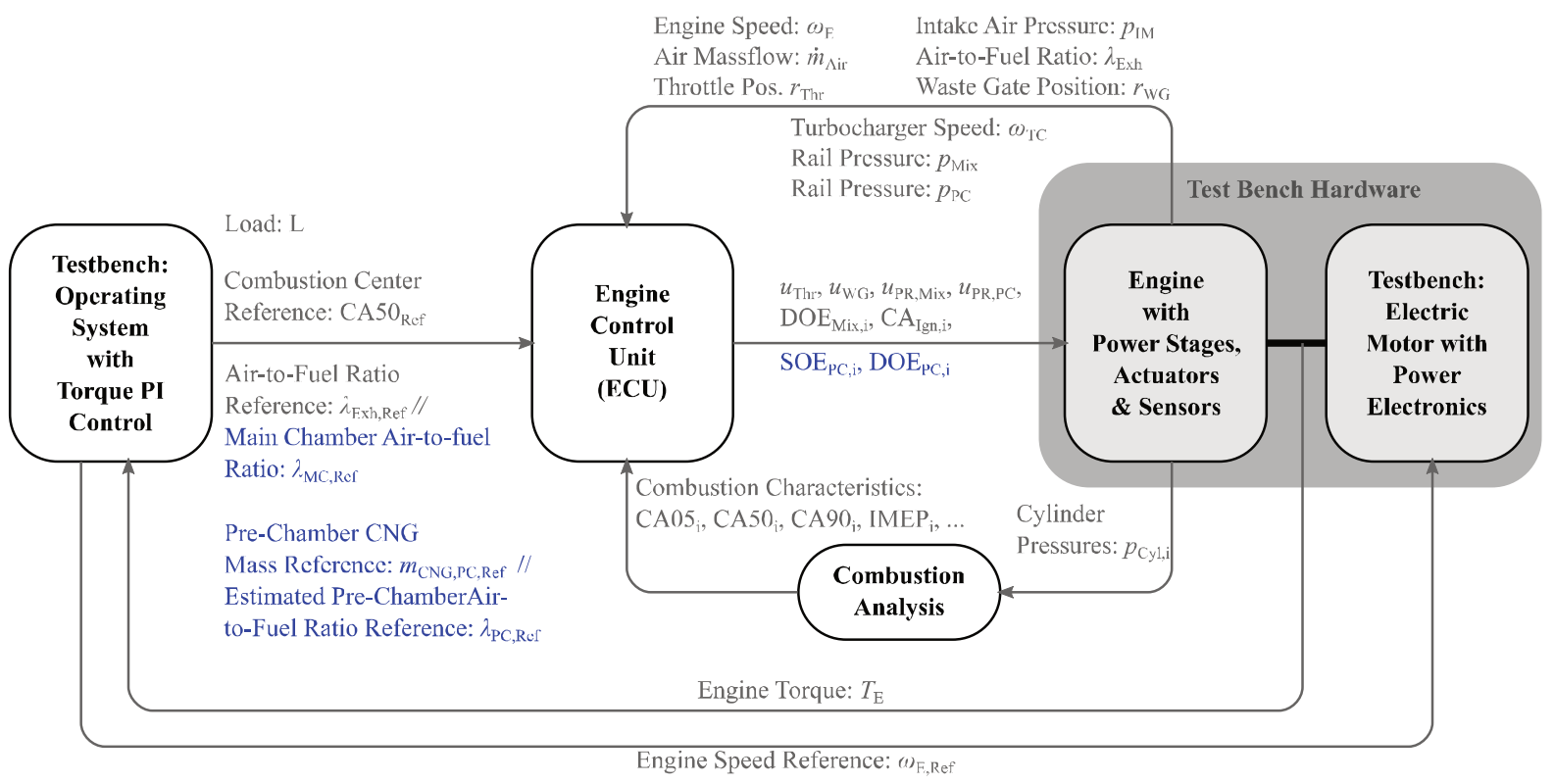

Fig. 2. Test bench setup of the research engines with the main signal flows used for the engine control. The test bench operating system sets four reference signals and the ECU uses feedback control to operate the engine accordingly. The blue reference and actuator signals are needed additionally for engine 2 with scavenged pre-chambers only 
For each of the four reference signals, the ECU has a control structure implemented. These control loops are described in the next subsections. The first three control structures (load, air-to-fuel ratio and combustion placement) are identical for both engines. They are based on control approaches presented in [6] and are adapted to fit the engine setup. The additional control tasks allowing to manually set the pre-chamber scavenging of engine 2 are explained in section 2.5 .

\subsection{Load control}

As depicted in Fig. 2, the test bench operating system controls the torque of the engine with a PI controller. The PI control output L is transferred to the ECU and represents the gas pedal signal of a car.

With this signal, the throttle and the waste gate position are controlled. Since we have two control outputs and one control input, we have one degree of freedom which can be used to achieve a desired engine performance. If we would want to optimize the dynamic behavior of the engine, we would have to close the waste gate at all times (except if the turbo charger speed increases above its limit and mechanical damage could occur) and control the engine with the throttle only. However, this strategy would lead to substantial pumping losses. The most fuel efficient strategy is to reduce pumping losses by operating the engine with completely open waste gate unless the throttle is completely open [5]. This strategy, illustrated in Fig. 3, was imple- mented on the ECU. With the assumption that the engine reaches a maximum intake manifold pressure of 2 bar, we reach a maximum load of approximately 50\% without charging. Therefore, below $50 \%$, the engine load is controlled by the throttle with open waste gate, and above $50 \%$, it is controlled by the waste gate valve with open throttle.

In Figure 4 the complete load control structure is illustrated. The load reference signal L from the test bench operating system is limited if the cylinder averaged indicated mean effective pressure (IMEP ${ }_{\text {Mean }}$ ) exceeds a predefined maximum level. This is necessary in order to protect the engine against mechanical damage. The limitation algorithm consists of an integral controller, which is limited to negative values and added to the unlimited load signal. A simplified version of the algorithm transfer function is stated in eq. (1). The algorithm implemented on the ECU additionally uses an anti-reset windup scheme to prevent integrator windup.

$$
\mathrm{L}_{\mathrm{Lim}}=\mathrm{L}+\min \left(0,\left(\mathrm{IMEP}_{\text {Max }}-\mathrm{IMEP}_{\text {Mean }}\right) \cdot \frac{\mathrm{k}_{\mathrm{i}}}{\mathrm{s}}\right)
$$

The limited load signal $\mathrm{L}_{\mathrm{Lim}}$ is used to derive a reference throttle and waste gate position according to the strategy presented in Fig. 3. The derived reference value for the throttle position is directly fed to a proportional-integralderivative (PID) controller, which adapts the duty cycle of the throttle $\mathrm{u}_{\mathrm{Thr}}$ accordingly. For the waste gate, a further

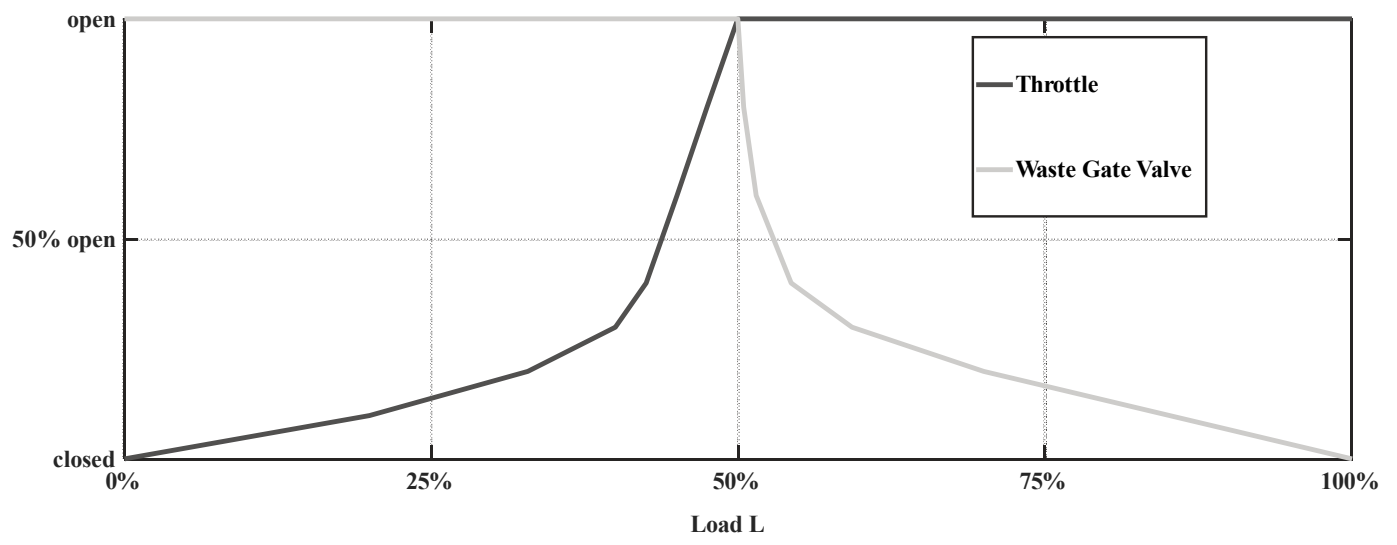

Fig. 3. Load control strategy, which is implemented on the ECU

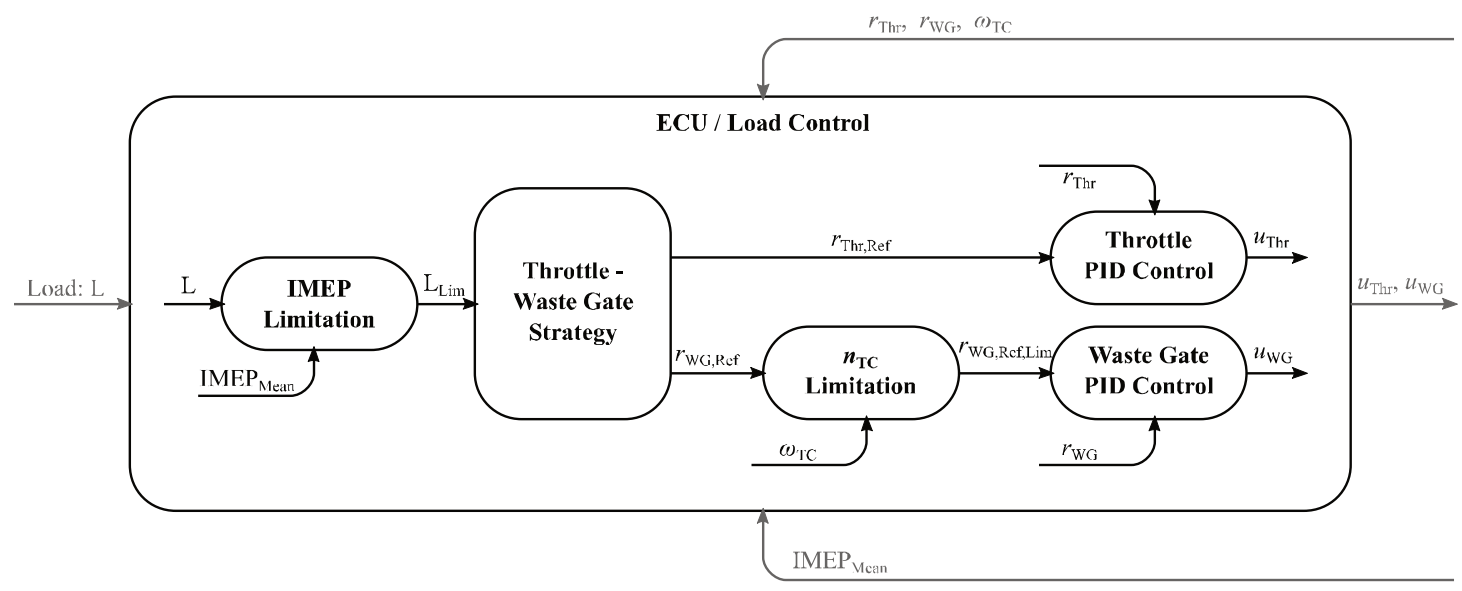

Fig. 4. Complete load control structure, implemented on the ECU 
control algorithm is needed in order to limit the turbo charger speed $\mathrm{n}_{\mathrm{TC}}$.

$$
\begin{aligned}
& r_{\mathrm{WG}, \text { Ref,Lim }}=r_{\mathrm{WG}, \operatorname{Ref}}-\left(\operatorname { m i n } \left(0,\left(\mathrm{n}_{\mathrm{TC}, \mathrm{Max}}-\mathrm{n}_{\mathrm{TC}}\right) .\right.\right. \\
& \left.\left.\frac{\mathrm{k}_{\mathrm{i}, \mathrm{Max}}}{\mathrm{s}}\right)+\max \left(0,\left(\mathrm{n}_{\mathrm{TC}, \text { Min }}-\mathrm{n}_{\mathrm{TC}}\right) \cdot \frac{\mathrm{k}_{\mathrm{i}, \mathrm{Min}}}{\mathrm{s}}\right)\right)
\end{aligned}
$$

Similar to the IMEP limitation, this algorithm sets lower and upper bounds to the turbocharger speed in order to protect it from physical damage. A simplified version of the algorithm transfer function neglecting the anti-reset windup scheme is stated in eq. (2). The limited waste gate position reference signal $r_{\mathrm{WG}, \text { Ref,Lim }}$ is fed into a PID controller, which controls the duty cycle $\mathrm{u}_{\mathrm{WG}}$ of the waste gate actuator.

\subsection{Air-to-fuel ratio control}

The air-to-fuel ratio in the exhaust manifold $\lambda_{\text {Exh }}$ is controlled by the CNG mass injected into the fresh air in front of the throttle by the CNG mixer. This mixer consists of 4 injectors, where each of them opens once in an engine cycle of $720^{\circ} \mathrm{CA}$. Over a cycle, all the injectors have the same opening duration.

The mass injected by one injector is influenced by the CNG rail pressure $\left(\mathrm{p}_{\mathrm{Mix}}\right)$ and the energizing duration of the injector $\left(\mathrm{DOE}_{\mathrm{Mix}}\right)$. Two actuators control one reference signal, which means that we have one degree of freedom, which we can use for optimization. Here, the chosen strategy is to have a continuous CNG stream into the air stream in order to guarantee a good mixing. Therefore, each injector should be opened for $\mathrm{DOE}_{\mathrm{Mix}, \mathrm{Ref}}=180^{\circ} \mathrm{CA}$ per cycle ${ }^{1}$.

The resulting control structure is illustrated in Fig. 5. It consists of a cascade control, with a fast and a slow control loop.

The fast loop controls the air-to-fuel ratio with the opening duration of the injectors. First, the CNG mass, which has to be injected in order to reach a desired reference airto-fuel ratio is calculated $\left(\mathrm{m}_{\mathrm{CNG}, \mathrm{Cyl}, \mathrm{Ref}}\right)$. This mass is corrected by a correction factor, derived by a PI feedback controller, which controls the air-to-fuel ratio to its reference. Together with the measured rail pressure $\mathrm{p}_{\text {Mix }}$ and an injector model, the corresponding duration of energizing $\left(\mathrm{DOE}_{\mathrm{Mix}}\right)$ is calculated and applied.
The slow cascade loop controls the rail pressure such that the injection duration takes values of approximately $180^{\circ} \mathrm{CA}$, depending on the precision of the CNG mass estimation. To reach that, an inverted injector model is used to calculate the mixer reference rail pressure, at which the opening duration reaches $180^{\circ} \mathrm{CA}$ for the given estimated CNG mass flow. A PID controller adapts the duty cycle $\left(\mathrm{u}_{\mathrm{PR}, \mathrm{Mix}}\right)$ of the pressure regulator in order to reach the corresponding reference rail pressure.

\subsection{Combustion placement (CA50 control)}

A common combustion control approach is to place the combustion such that the crank angle, at which $50 \%$ of the combustion energy is released (CA50), appears shortly after the top dead center. This can be done via a PI controller. Over several cycles, this controller places the spark advance such that the measured value CA50 corresponds to the reference value $\mathrm{CA} 50_{\text {Ref. }}$ This is done for each cylinder individually.

\subsection{Algorithms to manually set the pre-chamber scaven- ging}

For lean operation with $\lambda_{\text {Exh }}>1.7$, ignition of the charge becomes difficult, resulting in high cyclic variations and misfire. A possible solution to increase the provided ignition energy is using a scavenged pre-chamber, as introduced in engine 2. Figure 6 shows a schematic of its working principle. Instead of directly igniting the lean mainchamber, the spark plug ignites a richer mixture, created in a scavenged pre-chamber. This combustion increases the pressure in the pre-chamber, which causes the burning gas mixture to exit the pre-chamber through nozzles into the main chamber. These high-energy flame jets ignite the main chamber gas mixture and introduce additional turbulence, which increases the main-chamber combustion speed.

For engine operation with scavenged pre-chambers, the engine control unit is extended with additional functionalities.

To directly set the mass to be injected into each prechamber instead of the opening duration of the injectors, cylinder-individual injector maps are derived.

Further, an estimation algorithm of the air-to-fuel ratio inside of the pre-chamber at the time of ignition $\lambda_{\mathrm{PC}}$ is implemented on the engine control unit ${ }^{2}$. This estimation helps

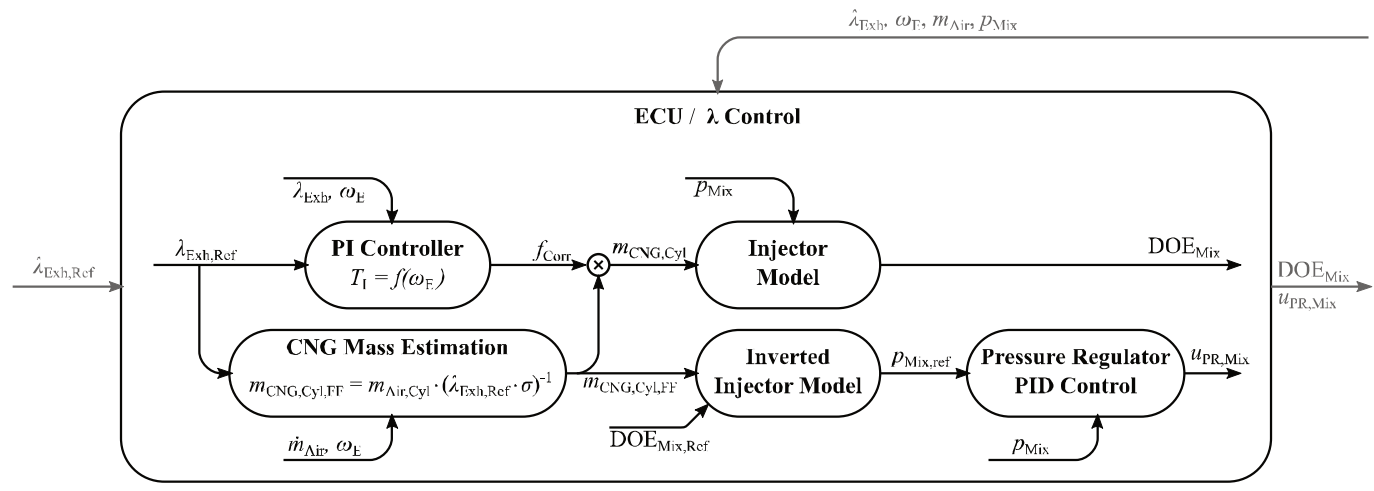

Fig. 5. Air-to-fuel control structure, implemented on the ECU with the according signals

\footnotetext{
${ }^{1}$ Here we assume that the energizing time corresponds to the opening duration of the injector. The error introduced due to this simplification is negligible.
}

${ }^{2}$ This approach has similarities with the pre-chamber air-to-fuel estimation presented in [9]. 
to choose the reference CNG mass to be injected in order to reach acceptable combustion conditions inside of the prechamber. Once the pre-chamber air-to-fuel ratio is known, the maximum energy $\mathrm{Q}_{\mathrm{PC}}$ can be calculated, which would be released by an instantaneous combustion inside of the pre-chamber at the time of ignition.

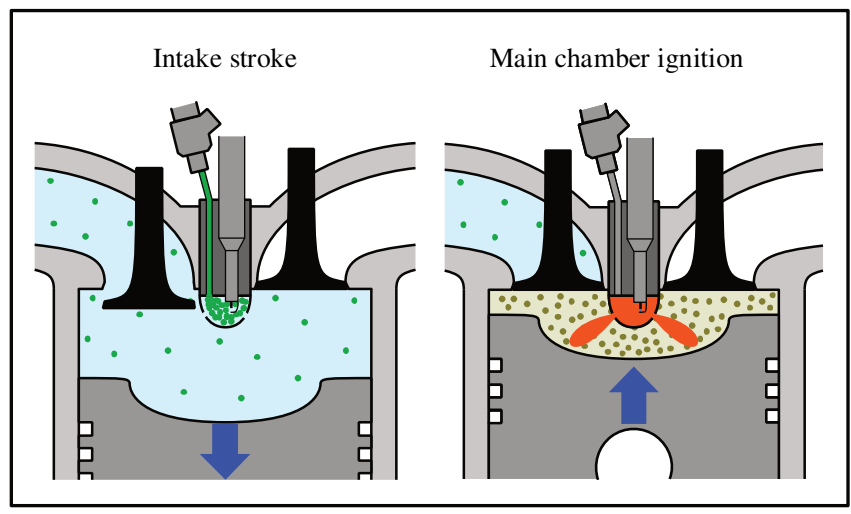

Fig. 6. Schematic of engine 2 operated with scavenged pre-chambers (graphics are taken from [13] and adapted)

The estimation algorithm uses the following simplifications:

- All gases are ideal, i.e. heat capacity ratios and isentropic coefficients are assumed to be independent of gas pressure and temperature.

- Prior to ignition, the pressure inside of the main chamber and the pre-chamber are equal.

- Isentropic compression is assumed during the compression stroke.

The algorithm is designed as follows:

- Using eq. (3), the air-to-fuel ratio of the main chamber before the CNG injection is calculated. The two CNG masses can either be measured, or calculated with injector maps. Also the cylinder (and pre-chamber) pressure at the end of the CNG injection into the pre-chamber is determined. It is equal to the intake pressure if the compression has not started yet, otherwise it is calculated assuming isentropic compression.

- The ideal gas law is used to calculate the volume which is filled by the injected $\mathrm{CNG}$ into the pre-chamber at the end of the pre-chamber injection. If this volume is larger than the pre-chamber volume, we assume that the whole pre-chamber is filled and any additional CNG is released into the main chamber through the nozzles of the pre-chamber. If the CNG volume is lower, the rest of the pre-chamber volume is assumed to be filled with the main-chamber air-CNG mixture.

- Assuming perfect mixing, the new air-to-fuel ratios of the main chamber and the pre-chamber after the $\mathrm{CNG}$ injection are calculated.

- Assuming an isentropic compression, the cylinder pressure and temperature of the gas mixture at the time of the ignition are calculated. At these conditions, the volume of the gas which originally filled the pre-chamber at the end of the CNG injection, is calculated. Subtracting this volume from the total pre-chamber volume equals the volume of the gas that had to enter the prechamber from the main chamber during the compression.

- Assuming perfect mixing, the air-to-fuel ratio of the pre-chamber at the time of ignition is calculated $\rightarrow \lambda_{\mathrm{PC}}$

- We limit the derived pre-chamber air-to-fuel ratio to values larger or equal to $1^{1}$ and use the definition of the air-to-fuel ratio to calculate the total $\mathrm{CNG}$ mass inside of the pre-chamber for which enough oxygen is available. Using this mass and the lower heating value of $\mathrm{CNG}$, we derive the maximum possible combustion energy inside of the pre-chamber at the time of ignition $\rightarrow \mathrm{Q}_{\mathrm{PC}}$.

$$
\lambda_{\mathrm{MC}}=\lambda_{\mathrm{Exh}} \cdot \frac{\dot{\mathrm{m}}_{\mathrm{CNG}, \mathrm{Mix}}+\dot{\mathrm{m}}_{\mathrm{CNG}, \mathrm{PC}}}{\dot{\mathrm{m}}_{\mathrm{CNG}, \mathrm{Mix}}}
$$

The described estimation algorithm is implemented on the engine control unit and allows to track the estimated pre-chamber conditions in real time. Further, the algorithm is inverted, in order to be able to set a desired pre-chamber air-to-fuel ratio $\lambda_{\mathrm{PC}, \mathrm{Ref}}$, which is translated to a CNG mass to be injected into the pre-chamber. This feed forward control strategy is illustrated in Fig. 7. Assuming that the estimation error is acceptable, this algorithm can be used to prepare an ignitable mixture inside of the pre-chamber at the time of ignition. However, having an ignitable gas mixture does not guarantee a sufficient ignition energy for the main chamber. The desired air-to-fuel mixture $\lambda_{\text {PC,Ref }}$ therefore still has to be adapted depending on the operating point and the air-to-fuel ratio inside of the main chamber.

\footnotetext{
${ }^{1}$ The limitation is only used for the calculation of $Q_{\mathrm{PC}}$, the air-tofuel ratio output $\lambda_{\mathrm{PC}}$ of the algorithm is unlimited.
}

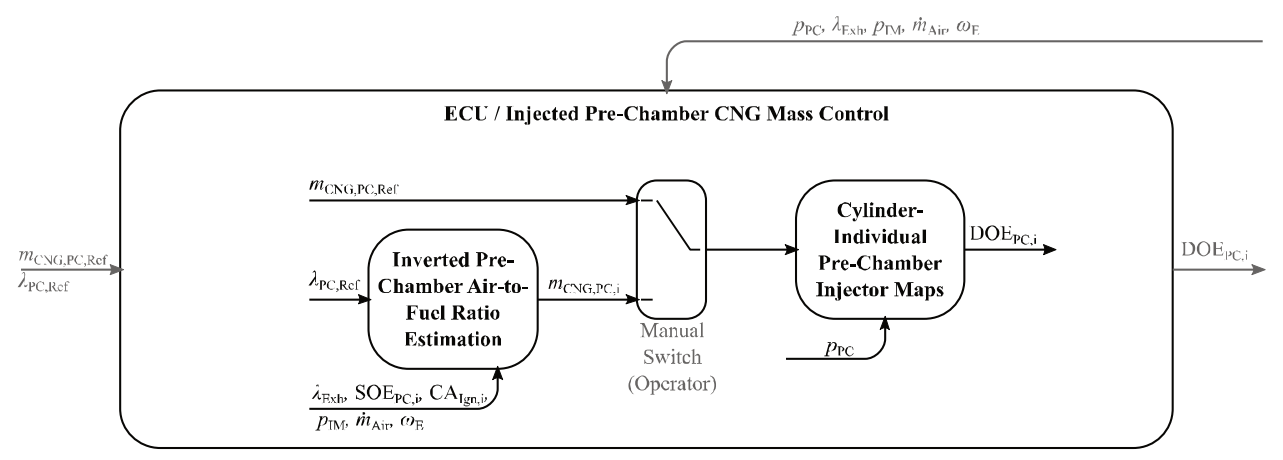

Fig. 7. Implemented feed forward functionalities for the pre-chamber scavenging. The operator can either set the desired air-to-fuel ratio inside of the prechambers at the time of ignition, or he can set the CNG mass to be injected directly 
The injection timing $\left(\mathrm{SOE}_{\mathrm{PC}, \mathrm{i}}\right)$ is fixed at $300^{\circ} \mathrm{BTDC}$ just after the exhaust valve closes, in order to avoid methane slip and to ensure that the injection finishes before the compression stroke starts. With an early injection timing, the injected CNG has the longest possible time to mix with the gas inside of the pre-chamber and the gas entering the pre-chamber during the compression stroke. An initial variation of the injection timing has shown that this strategy has a positive effect on hydrocarbon emissions.

\section{Pre-chamber scavenging analysis}

With the control algorithms described in section 2, the engine is operated in steady-state-condition in order to investigate the influence of scavenging on performance parameters (engine efficiency, combustion stability and emissions).

The objective of the conducted analysis is to understand the effects of scavenging, in order to extend the basic prechamber injection functionalities derived in section 2.5 with a feedback control algorithm. In consideration of the main chamber air-to-fuel ratio, engine load and engine speed, this feedback approach would be able to set the amount of CNG injected into the pre-chamber such that combustion stability and engine efficiency as well as emissions are improved.

\subsection{Analysis of an air-to-fuel ratio variation at a con- stant operating point}

Figure 8 shows a comparison of the spark plug engine 1, the un-scavenged (passive) engine 2 and the scavenged
(CNG injection enabled) engine 2. At constant engine speed and torque, the main chamber air-to-fuel ratio $\left(\lambda_{\mathrm{MC}}\right)$ is varied (The main chamber air-to-fuel ratio is calculated according to equation (3)). For the scavenged case (green), the amount of $\mathrm{CNG}$ injected into the pre-chambers is adapted manually in order to derive a stable combustion, indicated by a low IMEP covariance.

For air to fuel ratios $\lambda_{\mathrm{MC}}<1.6$, engine 2 has a lower efficiency with similar emission characteristics compared to the spark plug engine 1. Scavenging decreases efficiency even more while maintaining emission levels. For engine 1, the energy of the spark-plug is sufficient to reliably ignite the CNG-air mixture, and the combustion in the main chamber is fast already without the turbulence introduced by the flame jets of the pre-chamber nozzles. For engine 2, the pre-chamber increases the ignition energy and speeds up the combustion. However, the increased main-chamber combustion speed does not improve emissions or efficiency. Also the amount of CNG-air mixture burning inside of the pre-chamber does not contribute to the torque generation, because a main part of its energy is lost in turbulence and wall heat losses. Additional CNG injected into the prechambers (scavenging) further increases the energy loss in the pre-chambers without any positive effect on the main chamber combustion. We conclude that for air-to-fuel ratios $\lambda_{\mathrm{MC}}<1.6$, engine 2 with pre-chambers is outperformed by engine 1 with spark-plugs only. Also we see that for engine 2 , scavenging has a negative effect on engine efficiency.

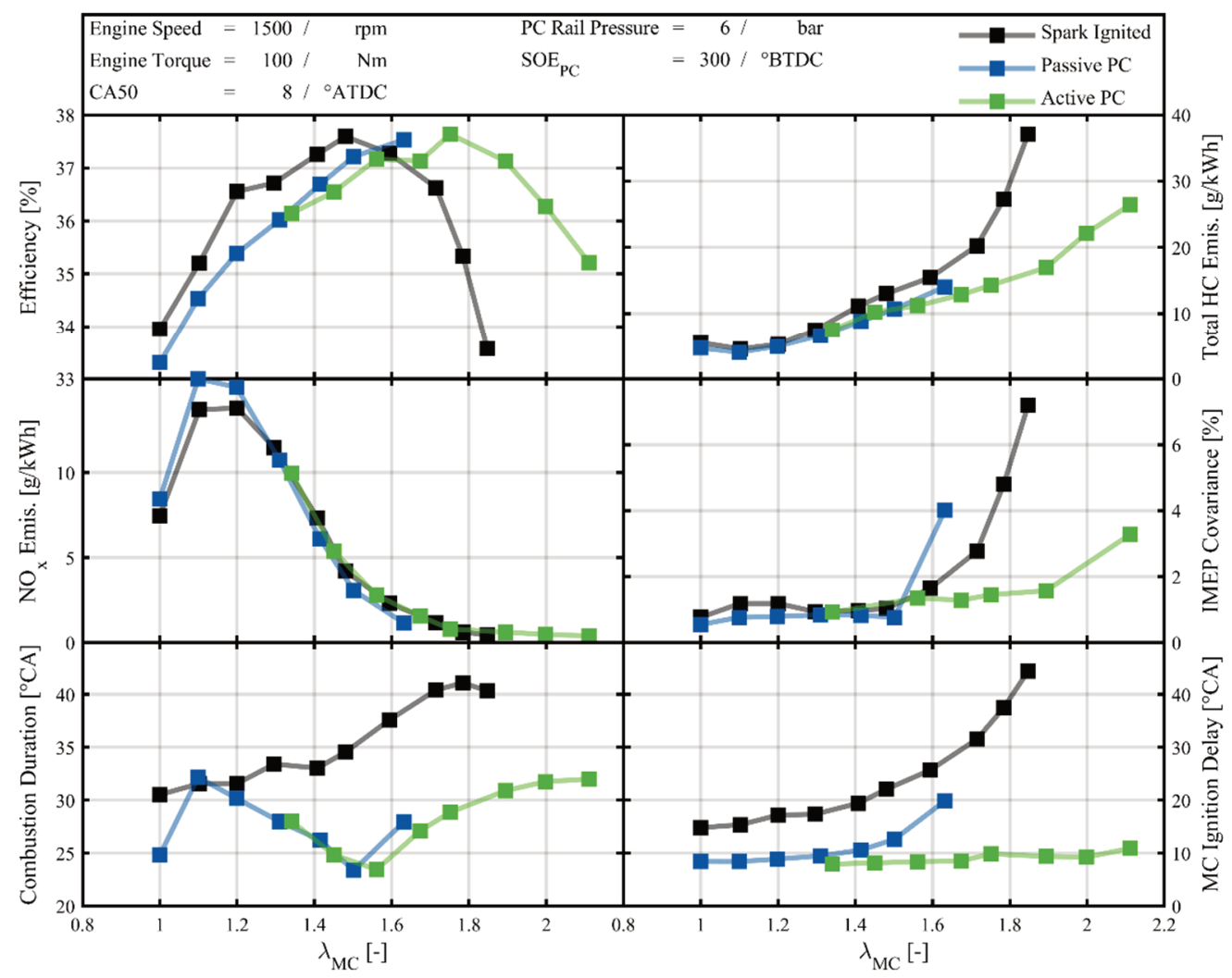

Fig. 8. Air to-fuel ratio variation at a medium load operating point with the spark-ignited engine 1 , the pre-chamber engine 2 without scavenging (passive $\mathrm{PC})$ and engine 2 with scavenging (active PC) ${ }^{1}$.

\footnotetext{
${ }^{1}$ Efficiency and emission values presented in this figure are measured with a different piston shape and pre-chamber shape compared to other results stated within this paper. Absolute values are not comparable to other graphics.
} 
For air-to-fuel ratios $\lambda_{\mathrm{MC}}>1.6$, engine 2 needs prechamber scavenging in order to ensure a stable combustion without misfire. In this region, it clearly outperforms engine 1 regarding efficiency, combustion stability and hydrocarbon emissions. We conclude that for very lean operation, the increased ignition energy and the additional turbulence introduced into the main chamber have a positive effect on engine efficiency and emissions. The spark ignition of engine 1 does not provide enough energy for a fast combustion anymore.

So far we have established that for $\lambda_{\mathrm{MC}}<1.6$ engine 1 performs better and scavenging has a negative effect, while for $\lambda_{\mathrm{MC}}>1.6$ engine 2 performs better and scavenging is necessary in order to reach acceptable combustion stability. Now we want to compare engine 1 with engine 2 for any choice of the air-to-fuel ratio with the efficiency as performance criterion. As we can see in Fig. 8 with spark-ignition only, we reach highest efficiency at $\lambda_{\mathrm{MC}}=1.5$ while the prechamber engine 2 reaches its efficiency maximum at $\lambda_{\mathrm{MC}}=$ $=1.7$. With this air-to-fuel ratio shift, we are able to drastically reduce $\mathrm{NO}_{\mathrm{x}}$ emissions without any penalty in hydrocarbon emissions or efficiency when switching from engine 1 to engine 2. This fact clearly shows the advantages of scavenged pre-chambers for lean $\mathrm{CNG}$ engine operation and motivates further analysis of pre-chamber scavenging.

\subsection{Analysis of a pre-chamber CNG injection variation at a constant operating point}

For very lean operation around $\lambda=1.8$, a variation of the CNG mass injected into the pre-chambers is analyzed. Measurement results including the estimated parameters described in section 2.5 are illustrated in Fig. 9. With the objective to study the influence of the pre-chamber combustion on the main chamber combustion and the resulting engine efficiency and emission characteristics, two measurement sets are compared. For a first measurement set (black), the air-to-fuel ratio in the exhaust is controlled to a constant value $\lambda_{\text {Exh }}=1.8$, as described in section 2.3. However, by increasing the amount of $\mathrm{CNG}$ injected into the pre-chamber, the amount of $\mathrm{CNG}$ in the main chamber has to be reduced in order to keep a constant overall air-tofuel ratio. Therefore, with increased $\mathrm{CNG}$ injection into the pre-chamber the mixture in the main chamber gets leaner, which influences the combustion characteristics. In order to study the effect of the pre-chamber combustion on the main-chamber combustion only, the main chamber gas composition has to be held constant. Hence, in a second (blue) measurement series, the air-to-fuel control algorithm described in section 2.3 is slightly adapted. An estimated air-to-fuel ratio of the main chamber air-to-fuel ratio $\lambda_{\mathrm{MC}}$ replaces the air-to-fuel ratio feedback signal $\lambda_{\text {Exh }}$ of the controller. The main chamber ratio is calculated according to eq. (3).

For a constant main chamber air-to-fuel ratio (blue) we find that the highest efficiency occurs at the fastest combustion with the lowest ignition delay and IMEP covariance. Also the hydrocarbon emissions are close to their minimum. Hence, for such lean mixtures and constant main chamber air-to-fuel ratio, we have to adjust the amount of $\mathrm{CNG}$ injected into the pre-chambers such that we reach the fastest possible combustion in the main chamber, which is the case for the lowest ignition delay. For the operation point chosen in Fig. 9, this is the case for an injected gas mass of $1 \mathrm{mg} / \mathrm{inj}$. Looking at the estimated signals described in section 2.5, we see that for this amount of injected $\mathrm{CNG}$, the pre-chamber has its highest combustion energy. Since the estimated pre-chamber air-to-fuel ratio is clearly below 1 at this injection rate, the pre-chamber energy depends on the amount of air inside of the pre-chamber only. The amount of air inside of the pre-chamber increases with increasing cylinder pressure. Hence for a constant combustion center, a shorter ignition delay leads to a later ignition at a higher cylinder pressure, which leads to a higher amount of air and therefore to a higher energy content $\mathrm{Q}_{\mathrm{PC}}$ in the pre-chamber.

We conclude that for a strategy where the main chamber air-to-fuel ratio is controlled to a constant value of $\lambda_{\mathrm{MC}}=$ $=1.8$ (or higher) and the combustion center is controlled to a constant value, there exists an optimal amount of CNG to be injected into the pre-chamber, which leads to the shortest ignition delay and to the highest ignition energy for the main chamber. Injecting a higher amount of CNG would produce too rich conditions and injecting a lower amount would lead to a weaker pre-chamber combustion with a lower ignition energy for the main chamber. With highest ignition energy, we reach fastest main chamber combustion, which leads to highest efficiency, best combustion stability and low hydrocarbon emissions compared to other injection rates.

For a constant $\lambda_{\text {Exh }}$, (black) we find that the efficiency maximum and the hydrocarbon emission minimum do not occur at the fastest combustion anymore. Due to the fact that the main chamber gas mixture gets leaner with a higher amount of injected CNG into the pre-chambers, these two maxima occur at lower injection rates already. We conclude that if we control the exhaust manifold air-to-fuel ratio $\lambda_{\text {Exh }}$ to a constant value, we cannot find the optimum efficiency by controlling the ignition delay (or the combustion duration) to its minimum anymore.

In Fig. 10, the variation depicted in Fig. 9 with $\lambda_{\mathrm{MC}}=$ $=1.8$ is compared with variations measured at main chamber air to fuel ratios of $\lambda_{\mathrm{MC}}=1.5$ (green) and $\lambda_{\mathrm{MC}}=1.7$ (yellow). For all variations, the highest pre-chamber energy leads to the lowest ignition delay and to the fastest main chamber combustion. However, the strategy to control towards fastest combustion duration or shortest ignition delay is not the favorable strategy for $\lambda_{\mathrm{MC}}=1.5$ or $\lambda_{\mathrm{MC}}=$ $=1.7$ anymore.

The engine efficiency maximum as well as lowest $\mathrm{NO}_{\mathrm{x}}$ emissions are derived with the lowest possible CNG injection $^{1}$ for $\lambda_{\mathrm{MC}}=1.5$. If we would inject an amount of 0.8 $\mathrm{mg} / \mathrm{inj}$ in order to reach a minimum combustion speed, we would increase the NOx emissions by approximately 1.2 $\mathrm{g} / \mathrm{kWh}$ and decrease the efficiency by approximately $0.75 \%$ compared to the lowest possible CNG pre-chamber injection. Figure 8 in section 3.1.shows that for a main-chamber air-to-fuel ratio of $\lambda_{\mathrm{MC}}=1.5$, no scavenging leads to a better performance than scavenging. Therefore, we assume here that no scavenging would further improve engine perfor-

\footnotetext{
${ }^{1}$ The minimum amount to inject is dependent on injector characteristics and the rail pressure.
} 
mance compared to the lowest possible CNG injection into the pre-chamber. We conclude that the combustion is already fast enough without any further $\mathrm{CNG}$ injection into the pre-chamber. A further increase of the combustion speed would lead to increased wall heat losses inside of the pre-chamber and the main chamber and therefore negatively influence the engine efficiency as well as the $\mathrm{NO}_{\mathrm{x}}$ emissions.

At a main chamber air-to-fuel ratio $\lambda_{\mathrm{MC}}=1.7$ we have to inject a minimum amount of CNG in order to guarantee a stable combustion without misfiring. This minimum amount also leads to best efficiency and lowest $\mathrm{NO}_{\mathrm{x}}$ emissions. However, compared to $\lambda_{\mathrm{MC}}=1.5$, hydrocarbon emissions and combustion stability can be slightly improved without substantial efficiency reduction by a small increase from the minimum injected amount to about $0.3 \mathrm{mg} / \mathrm{inj}$. Using an amount of $1.2 \mathrm{mg} / \mathrm{inj}$ in order to reach fastest combustion and lowest ignition delay would decrease the efficiency by $0.75 \%$ and increase $\mathrm{NO}_{\mathrm{x}}$ emissions by 0.75 $\mathrm{g} / \mathrm{kWh}$. However, hydrocarbon emissions would be decreased by $0.6 \mathrm{~g} / \mathrm{kWh}$.

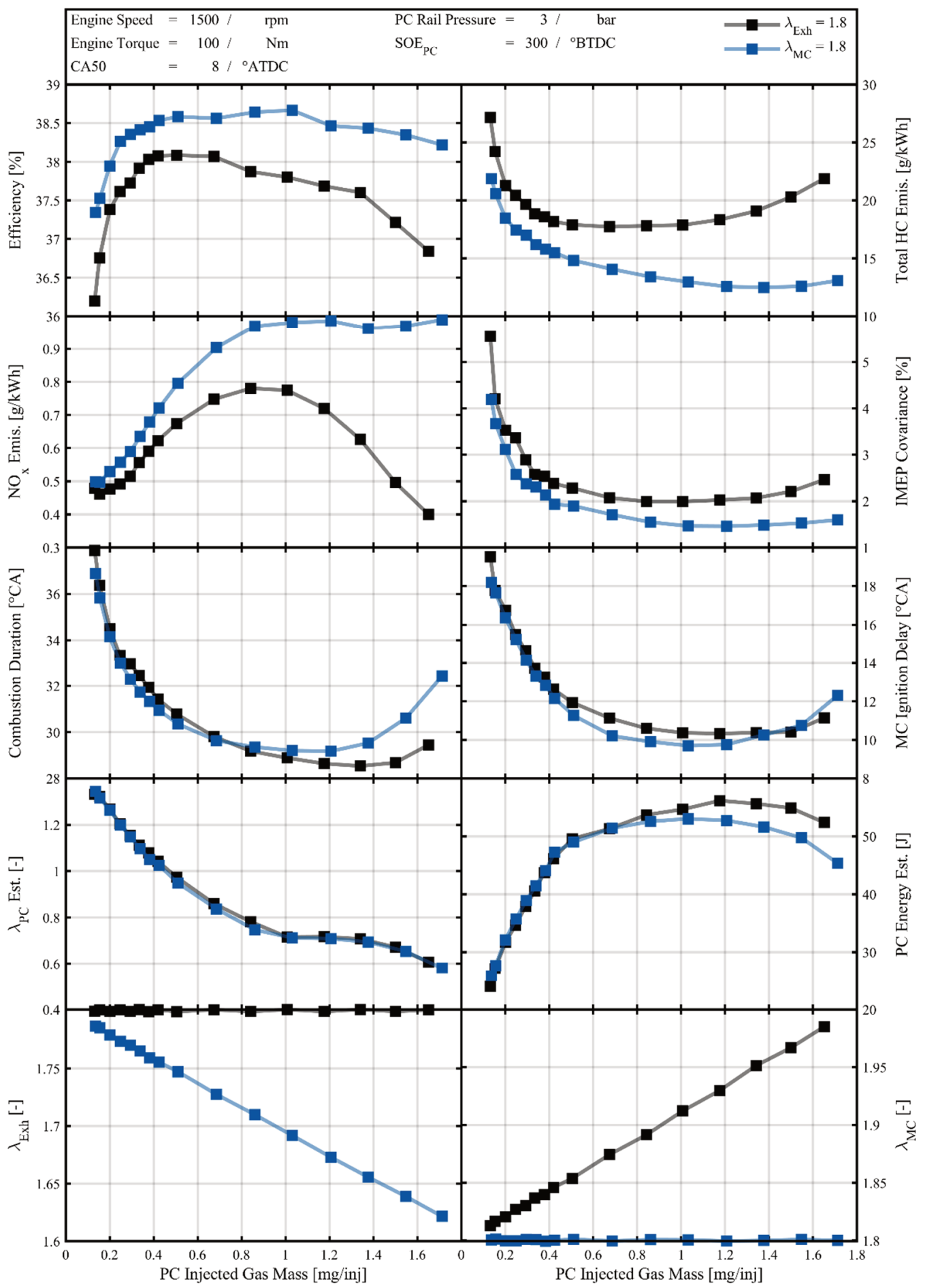

Fig. 9. Variation of the CNG mass injected into the pre-chambers. For the first (black) measurement series, the exhaust gas air-to-fuel ratio was controlled to $\lambda_{\mathrm{Exh}}=1.8$ and for the second (blue) measurement series, the main-chamber air-to-fuel ratio was controlled to $\lambda_{\mathrm{MC}}=1.8$ 


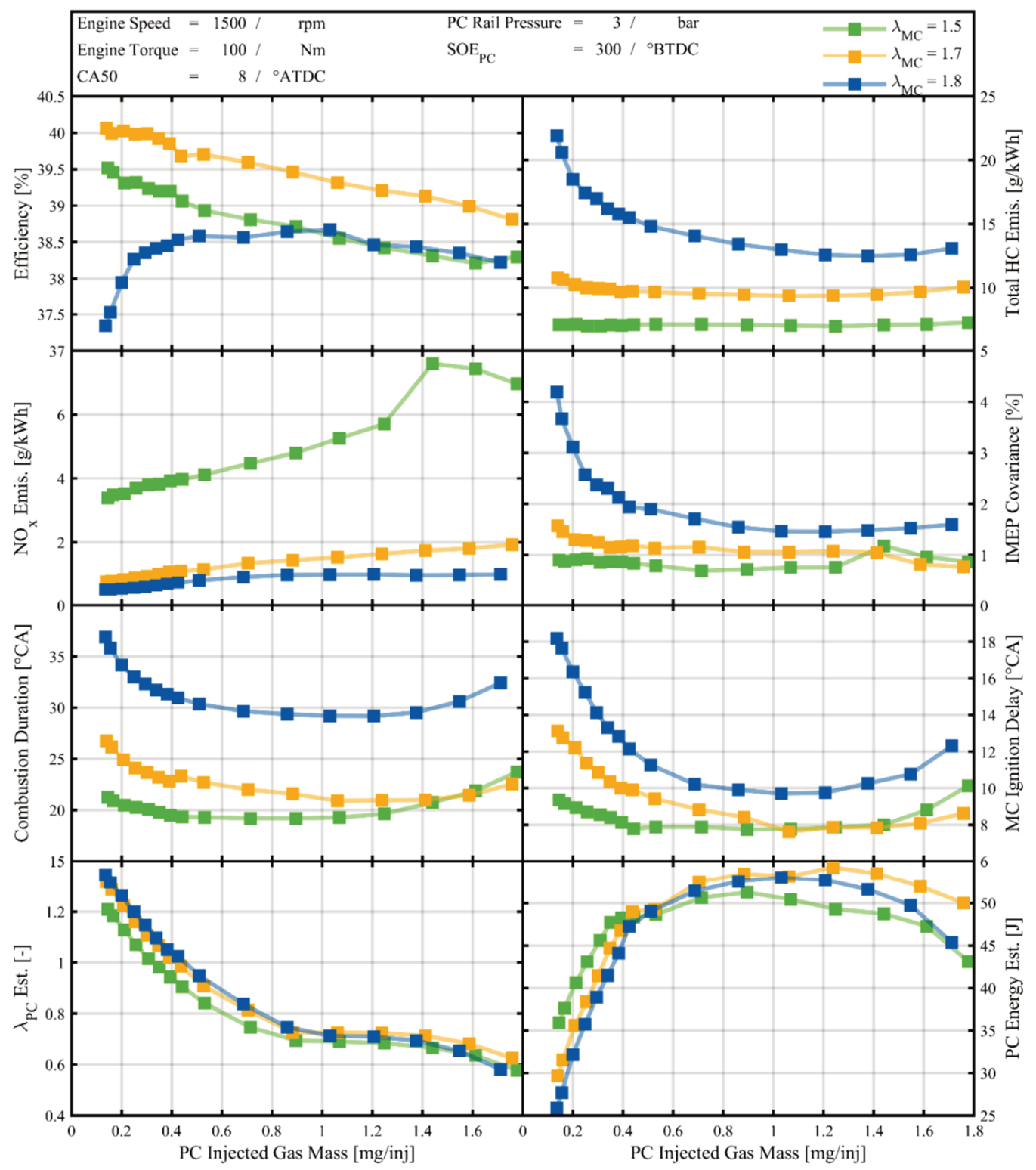

Fig. 10. Comparison of the pre-chamber injection variation depicted in Fig. 9 measured at $\lambda_{\mathrm{MC}}=1.8$ with injection variations measured at $\lambda_{\mathrm{MC}}=1.5$ and $\lambda_{\mathrm{MC}}=1.7$

A possible control strategy to compensate for changes in the main chamber air-to fuel ratio at a given engine speed and torque is to control the ignition delay to a reference value. Looking at Fig. 10, a PID controller with a reference ignition delay of $11^{\circ} \mathrm{CA}$ would control the injected CNG amount to $[0.0,0.3,0.5] \mathrm{mg} / \mathrm{inj}$ for the main chamber airto-fuel ratios $[1.5,1.7,1.8]$. these injection rates would lead to optimal results for $\lambda_{\mathrm{MC}}=1.5$ and $\lambda_{\mathrm{MC}}=1.7$, and acceptable results for $\lambda_{\mathrm{MC}}=1.8$. For air-to-fuel ratios higher than approximately $\lambda_{\mathrm{MC}}=1.75$, we assume to reach better results by controlling the ignition delay to its minimum.

\subsection{Speed and torque variation at a constant air-to-fuel ratio}

As derived in [10], the engine has its maximum efficiency close to an air-to-fuel ratio of $\lambda_{\text {Exh }}=1.7$. At this ratio, an operation point variation is conducted in order to investigate the effects of engine speed and load on prechamber scavenging. For this variation, the amount of $\mathrm{CNG}$ injected into the pre-chamber was manually adjusted to an optimal value, which leads to best efficiency as well as high combustion stability and low emissions. Results of this variation are illustrated in Fig. 11. We see that the amount of injected $\mathrm{CNG}$, optimized for best efficiency, is kept rather small for all operation points, however, it seems to be dependent on engine speed and load, and not straight forward to derive.

While engine efficiency and emissions are mainly dependent on engine torque, the combustion duration and the ignition delay are dependent on the engine speed only. Further we know from scavenging variations that the ignition delay reacts sensitive to low amounts of injected CNG. Both these facts can be used for the development of a highlevel scavenging control. Concluding, an ignition delay control to a reference value depending on the engine speed only, could be a well working strategy to control the engine while operating around $\lambda_{\mathrm{MC}}=1.7$, where best engine efficiency is found. 


\section{Proposal for an extended pre-chamber scaven- ging control}

Using the knowledge gathered in section 3 , we propose a high-level feedback control strategy for the operation of engine 2 with scavenged pre-chambers. This strategy derives the reference values for the injected pre-chamber
CNG mass and the pre-chamber rail pressure and therefore extends the functionalities presented in section 2.5. With this extension, the test-bench operator does not have to adapt these two set-values manually anymore. This extended control strategy proposal is depicted in Fig. 12. Further subsections explain its aspects in detail.

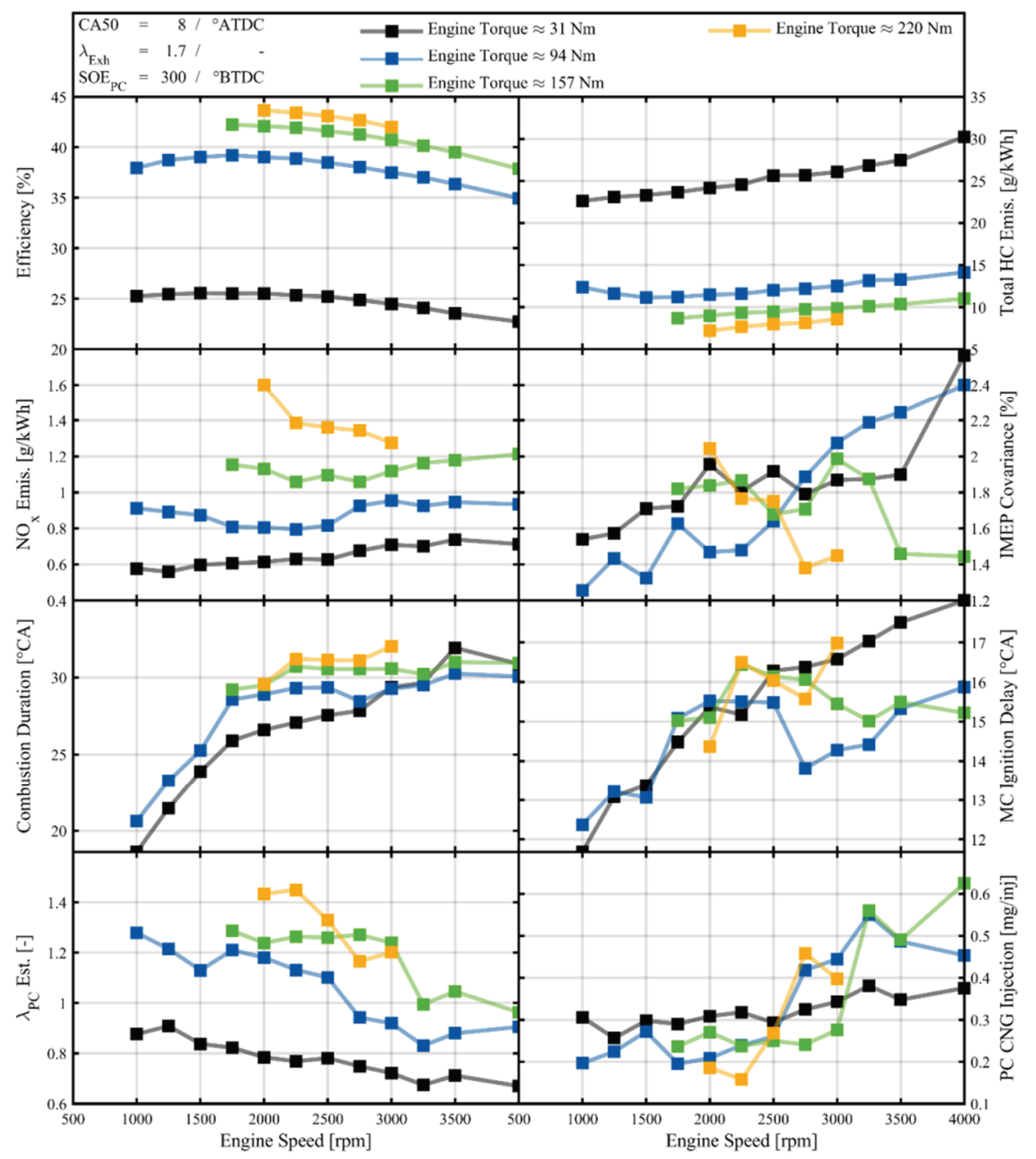

Fig. 11. Engine speed and load variation at an air-to-fuel ratio of $\lambda_{\text {Exh }}=1.7$. The amount of CNG injected into the pre-chambers is adapted manually with the objective to increase engine efficiency and emissions for each operating point

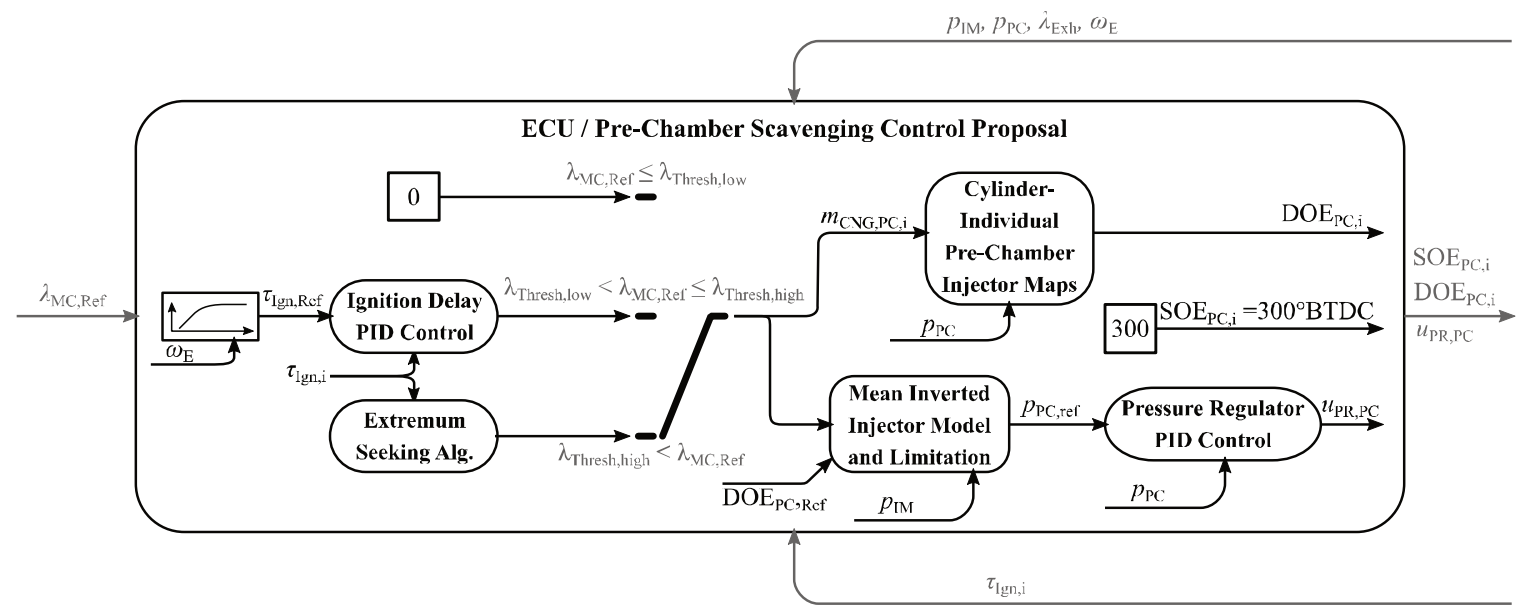

Fig. 12. Extended pre-chamber scavenging control suggestion. Depending on the main chamber air-to-fuel ratio, the strategy is to either control the ignition delay with the amount of CNG injected into the pre-chamber, or to minimize the ignition delay with an extremum seeking algorithm. For lower $\lambda_{\mathrm{MC}, \mathrm{Ref}}$ values, no injection is needed. Acceptable values for the strategy switching thresholds are $\lambda_{\text {Thresh,low }}=1.6$ and $\lambda_{\text {Thresh,high }}=1.75$ 


\subsection{Main chamber air-to-fuel control}

For scavenged operation, we propose to control the main-chamber air-to-fuel ratio instead of the exhaust gas air-to-fuel ratio, using the estimation depicted in equation (3). This approach allows to keep main chamber conditions constant, independent of the CNG amount directly injected into the pre-chamber. It decouples direct injection and mixer injection control, and it allows to control the ignition delay to its minimum in order to reach the efficiency maximum, as depicted in Fig. 9. This main chamber air-to-fuel feedback control approach was successfully implemented on the ECU.

\subsection{Pre-chamber rail pressure control suggestion}

Similar to the rail pressure control presented in section 2.3 and illustrated in Fig. 5, we propose to control the rail pressure such that the injection ends before the compression stroke starts. With an injection start at $300^{\circ} \mathrm{BTDC}$, the reference duration of injection $\mathrm{DOE}_{\mathrm{PC}, \mathrm{Ref}}$ has to be set to $120^{\circ} \mathrm{CA}$. An inverted pre-chamber injector map, then uses this reference injection duration and the amount of injected $\mathrm{CNG}$ to calculate the reference pre-chamber rail pressure. A further aspect to consider is that the pressure difference between rail and pre-chamber has to be at least 2 bar, in order to open a back pressure valve in front of the prechamber (see [10]). Therefore, the intake pressure plus 2 bar acts as a lower bound on the pre-chamber rail pressure reference value.

This control strategy therefore sets the lowest possible pre-chamber rail pressure, which is still able to open the back pressure valve and ensures that the $\mathrm{CNG}$ pre-chamber injection finishes before the compression stroke starts. A low rail pressure is desired because it allows to inject a lower minimum amounts of CNG into the pre-chamber and it increases the control sensitivity.

\subsection{Pre-chamber injection duration control suggestion}

As depicted in Fig. 12, the control strategy for the CNG injection depends on the main chamber air-to-fuel ratio.

For values lower than a threshold $\lambda_{\text {Thresh,low }}$, there is no need of injecting any additional CNG into the pre-chamber. The mass entering from the main chamber during the compression stroke is sufficient to cause a pre-chamber combustion able to reliably ignite the main chamber and introduce enough turbulence for a fast combustion.

For air-to-fuel ratios between $\lambda_{\text {Thresh,low }}$ and $\lambda_{\text {Thresh,high }}$ we would like to guarantee a stable combustion without misfire, which only needs a small amount of injected CNG mass, lower than the mass which leads to the fastest combustion. The proposed strategy is to adjust the injected CNG mass in order to control the ignition delay to a reference value, depending on the engine speed. This control compensates for changes in the air-to-fuel ratio to a certain extent. Also, as depicted in Fig. 11, the ignition delay seems to be independent of the engine torque. Therefore, the reference value is a function of the engine speed only. However, this control approach can only be applied for a limited range of injected CNG mass. Due to the quadratic shape of the ignition delay, a linear controller is only stable as long as the gradient of the ignition does not change its sign.
At main chamber air-to-fuel ratios higher than an upper threshold $\lambda_{\text {Thresh,high, }}$ we want to control the ignition delay to its minimum in order to minimize the combustion duration, which improves efficiency and hydrocarbon emissions as well as the combustion stability. Classic adaptive algorithms capable of that are generally referred to as extremum seeking [11]. Applied to the control problem described here, an extremum seeking algorithm would use an excitation signal to vary the CNG mass injected into the prechamber in every cycle. By comparing the ignition delays of these injection masses, the algorithm derives the ignition delay gradient. This gradient is then controlled to zero by an I-controller. Algorithms of higher complexity would estimate the quadratic shape of the ignition delay depending on the injected CNG mass [3]. Using these shape parameters, they would calculate the position of the shape minimum and set the CNG mass accordingly.

The minimization of the ignition delay suggested here has similarities to the Diesel minimal control algorithm proposed in [12], which is used to control the combustion placement of a Diesel ignited CNG engine. For this engine, the start of Diesel injection is set such that the amount of Diesel needed to derive a desired combustion center is minimized. For a constant operating point, this control increases the CNG-Diesel ratio, which reduces $\mathrm{CO}_{2}$ emissions due to the higher hydrogen-carbon ratio of $\mathrm{CNG}$. However, while for the Diesel ignited CNG engine the ignition energy (injected Diesel) is minimized, the extremum seeking algorithm proposed here for engine 2 maximizes the ignition energy in order to derive the fastest possible combustion.

\section{Conclusions}

A detailed analysis of pre-chamber scavenging at lean engine operation revealed that early pre-chamber injection leads to an increased homogeneity of the CNG-air mixture inside of the pre-chamber, which leads to lower hydrocarbon emissions. The amount of CNG injected into the prechamber affects combustion stability, engine efficiency and engine emissions. For air-to-fuel ratios below 1.6, scavenging has negative effect. For higher air-to-fuel ratios, a small amount of $\mathrm{CNG}$ is needed in order to guarantee robust combustion without misfiring. For air-to-fuel ratios above 1.8 , there exists an optimal amount of CNG to be injected, which minimizes ignition delay and combustion duration, and optimizes efficiency and hydrocarbon emissions, as well as combustion stability. An extremum seeking algorithm which minimizes the ignition delay is proposed to control the pre-chamber scavenging.

Best engine efficiency is derived with a main-chamber air-to-fuel ratio of 1.7. For this ratio an engine speed and torque variation indicates that a small amount of $\mathrm{CNG}$ injected into the pre-chamber leads to best engine performance. This amount is dependent on speed and load, however, the ignition delay is sensitive to changes of the injected CNG mass and is only dependent on engine speed. Hence it is a suitable parameter for the pre-chamber scavenging feedback control. 


\section{Acknowledgements}

The work presented is part of the Horzon2020 project "GasOn". The authors would like to thank the project partners VW for their hardware support and the laboratory for aerothermochemistry and combustion (LAV) at ETH Zurich for fruitful discussions and the exchange of OD models.

The Swiss partners have been supported by the Swiss State Secretariat for Education, Research and Innovation (SERI) under contract number 15.0145-1.

\section{Funding}

This project has received funding from the European Union's Horizon 2020 research and innovation programme under grant agreement No 652816.

The Swiss partners have been supported by the Swiss State Secretariat for Education, Research and Innovation (SERI) under contract number 15.0145-1. The opinions expressed and arguments employed herein do not necessarily reflect the official views of the Swiss Government.

Further, the authors have been supported and supervised by researchers of the Research Unit (FOR) 2401, which is funded by the German Research Association (Deutsche Forschungsgemeinschaft, DFG).

\section{Bibliography}

[1] ATTARD, W.P., TOULSON, E., HUISJEN, A. et al. Spark ignition and pre-chamber turbulent jet ignition combustion visualization. SAE 2014 World Congress Exhibition, 8232012.

[2] BACH, C., LÄMMLE, C., BILL, R. et al. Clean engine vehicle a natural gas driven Euro-4/SULEV with $30 \%$ reduced $\mathrm{CO}_{2}$-emissions. SAE Technical Paper 2004-01-0645. 2004. DOI:10.4271/2004-01-0645.

[3] BERTSEKAS, D.P., P.D. Dynamic programming and optimal control. Athena Scientific, 1995.

[4] CATON, J.A. A comparison of lean operation and exhaust gas recirculation: thermodynamic reasons for the increases of efficiency. SAE Technical Paper 2013-01-0266. 2013. DOI:10.4271/2013-01-0266.

[5] ERIKSSON, L., FREI, S., ONDER, C. et al. Control and optimization of turbocharged spark ignited engines. IFAC Proceedings Volumes. 2002, 35. DOI:10.3182/20020721-6ES-1901.01515.

[6] GUZZELLA, L., ONDER, C.H. Introduction to modeling and control of internal combustion engine systems. Berlin, Heidelberg: Springer Berlin Heidelberg, 2010.

[7] KHAN, M.I., YASMIN, T., SHAKOOR, A. Technical overview of compressed natural gas $(\mathrm{CNG})$ as a transporta-

Severin Hänggi, MEng. - Swiss Federal Institute of Technology, Zürich (Switzerland)

e-mail: SHaenggi@idsc.mavt.ethz.ch

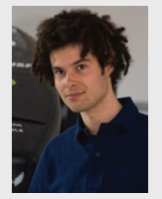

Patrik Soltic, DEng. - ETH, Empa, Swiss Federal Laboratories for Materials Science and Technology, Dübendorf, Switzerland.

e-mail:Patrik.Soltic@empa.ch

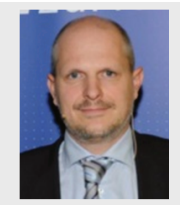

Richard Hutter, MEng. - ETH, Swiss Federal Institute of Technology, Zürich (Switzerland).

e-mail:RiHutter@idsc.mavt.ethz.ch

tion fuel. Renewable \& Sustainable Energy Reviews. 2015, 51, 785-797. DOI:10.1016/J.RSER.2015.06.053.

[8] KÜNG, L., BÜTLER, T., GEORGES, G. et al. Decarbonizing passenger cars using different powertrain technologies: Optimal fleet composition under evolving electricity supply. Transportation Research Part C: Emerging Technologies. 2018, 95, 785-801. DOI:10.1016/J.TRC.2018.09.003.

[9] SHAH, A. Improving the efficiency of gas engines using pre-chamber ignition. University of Lund, 2015.

[10] SOLTIC, P., HILFIKER, T., HUTTER, R., HÄNGGI, S. Experimental comparison of efficiency and emission levels of four-cylinder lean-burn passenger car-sized CNG engines with different ignition concepts. Combustion Engines. 2018, 176(1), 29-37. DOI: 10.19206/CE-2019-104.

[11] TAN, Y., MOASE, W.H., MANZIE, C. et al. Extremum seeking from 1922 to 2010. Control Conf (CCC), 2010, 29th Chinese 2010, 14-26.

[12] ZURBRIGGEN, F., HUTTER, R., ONDER, C. Dieselminimal combustion control of a natural gas-diesel engine. Energies. 2016, 9, 58. DOI:10.3390/en9010058.

[13] ZURBRIGGEN, F.J. Combustion control of a natural gasdiesel engine - feedback control and adaptation. ETH Dissertation 2016.

Thomas Hilfiker, Eng. - Empa, Swiss Federal Laboratories for Materials Science and Technology, Dübendorf, Switzerland.

e-mail: Thomas.Hilfiker@empa.ch

Prof. Christopher Onder, DEng. - ETH, Swiss Federal Institute of Technology, Zürich, Switzerland. e-mail: Onder@idsc.mavt.ethz.ch

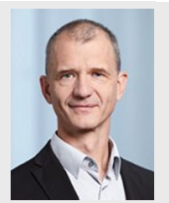

